\title{
HUBUNGAN PENGANEKARAGAMAN PANGAN DAN PEMBERIAN ASI EKSKLUSIF DENGAN KEJADIAN STATUS GIZI KURANG PADA BALITA UMUR 1-5 TAHUN (Studi Di Wilayah Kerja Puskesmas Kota Wilayah Utara Kota Kediri)
}

\author{
Endah Retnani Wismaningsih \\ Oktovina Rizky Indrasari \\ Rully Andriani \\ Institut Ilmu Kesehatan Bhakti Wiyata Kediri
}

\begin{abstract}
Food's diversification and exclusive breastfeeding's provision are the risk factors which may cause malnutrition. Java health government's data shows the prevalence of malnutrition was $18,4 \%$ in $200717,9 \%$ in $201012.6 \%$ in 2012 and increase to $13.26 \%$ in 2013. The purpose this research isthe was correlation between food's diversification and exclusive breastfeeding's provision with toddler's malnutrition status aged 1-5 years old.This type of research is analytic survey using Total sampling techniques with total sample is 33. To analyze, this research used bivariate analyze using chi-square and multivariate analyze Multiple Linier Regression.From the result, the bivariate test show that toddler's with no diversification were 6 time more risk of having malnutrition, and toddler's with no exclusive breastfeeding were 7 time more risk of having malnutrition. From the multivariate test showed that there was significance correlation of $0,000<0.05$ and $R=78,8$. The Conclution is there was strong correlation between food's diversification and exclusive breastfeeding's provision with toddler's malnutrition status aged 1-5 years old. That is by 78.8 it that both independent variable's showed have strong correlation with the status of malnutrition in toddlers aged 1-5 years.
\end{abstract}

Keywords: food's diversification, exclusive breastfeeding provision, malnutrition status, toddler

\begin{abstract}
Abstrak: Penganekaragaman Pangan dan Pemberian ASI Eksklusif merupakan faktor risiko yang dapat menimbulkan gizi kurang. Data Dinas Kesehatan Jawa Timur menunjukkan prevalensi gizi kurang yaitu sebesar 18,4\% pada tahun $2007,17,9 \%$ tahun 2010, 12,6\% pada tahun 2012 dan meningkat pada tahun 2013 sebesar 13,6\%.Penelitian ini bertujuan untuk mengetahui hubungan penganekaragaman pangan dan pemberian ASI eksklusif dengan kejadian status gizi kurang pada balita umur 1-5 tahun. Jenis Penelitian adalah survey analitik dengan menggunakan teknik sampling total sampling dengan total sampel 33. Analisa yang digunakan analisa bivariat menggunakan ChiSquaredan multivariat menggunakan Regresi Linier Berganda.Hasil analisa bivariat menunjukkan bahwa balita yang tidak mendapat penganekaragaman pangan berisiko 6 kali lipatmengalami gizi kurang dan balita dengan pemberian ASI yang tidak eksklusif lebih berisiko 7 kali lipat mengalami gizi kurang. Hasil analisa multivariat menunjukkan bahwa nilai signifikansi $0,000<0,05$, dan nilai $\mathrm{R}=78,8$. Kesimpulan dari penelitian ini bahwa penganekaragaman pangan dan pemberian ASI eksklusif memiliki hubungan dengan kejadian status gizi kurang pada balita umur 1-5 tahun. Sebesar 78,8, hal ini menunjukkan variabel independen memiliki hubungan yang kuat dengan kejadian status gizi kurang pada balita umur1-5 tahun.
\end{abstract}

Kata kunci: penganekaragaman pangan, pemberian ASI eksklusif, status gizi kurang, balita

Gizi kurang adalah gangguan kesehatan akibat kekurangan atau ketidakseimbangan zat gizi yang diperlukan untuk pertumbuhan, aktivitas berfikir dan semua hal yang berhubungan dengan kehidupan. 
Secara Nasional, prevalensi berat badan kurang pada tahun 2013, terdapat $13,9 \%$ balita berstatus gizi kurang. Jika dibandingkan dengan angka prevalensi nasional tahun $2007(18,4 \%)$ dan tahun $2010(17,9 \%)$, prevalensi kekurangan gizi pada balita tahun 2013 terlihat meningkat. Pada tahun 2010 terdiri dari $13,0 \%$ balita berstatus gizi kurang. Untuk mencapai sasaran Millenium Development Goals (MDGs) tahun 2015 yaitu $15,5 \%$ maka prevalensi gizi burukkurang secara nasional harus diturunkan sebesar $4.1 \%$ dalam periode 2013 sampai 2015 (Riskesdas ,2013).

Kasus balita gizi kurang masih banyak ditemui di Kota Kediri yakni sebesar 3,5\% atau 617 balita pada tahun 2014 (Dinkes Kota Kediri, 2014) dan pada tahun 2013 sebesar 3,4\% atau 500 balita (Dinkes Kota Kediri, 2013).

Masalah gizi sangat terkait dengan ketersediaan dan aksesibilitas pangan penduduk. Rendahnya aksesibilitas pangan (kemampuan rumah tangga untuk selalu memenuhi kebutuhan pangan anggotanya) mengancam penurunan konsumsi Makanan yang beranekaragam, bergizi-seimbang, dan aman di tingkat rumah tangga. Pada akhirnya akan berdampak pada semakin beratnya masalah kurang gizi masyarakat, terutama pada kelompok rentan yaitu ibu, bayi dan anak (BAPPENAS, 2011).

Selain penganekaragaman pangan yang dapat menyebabkan terjadinya status gizi kurang pada balita adalah pemberian ASI Eksklusif. Terjadinya rawan gizi pada bayi disebabkan antara lain oleh karena ASI (Air Susu Ibu) banyak diganti oleh susu formula dengan jumlah dan cara yang tidak sesuai kebutuhan. ASI merupakan Makanan yang bergizi yang mudah dicerna oleh bayi dan langsung diserap. Diperkirakan $80 \%$ dari jumlah ibu yang melahirkan mampu untuk menghasilkan air susu ibu dalam jumlah yang cukup untuk keperluan bayinya secara penuh tanpa Makanan tambahan bahkan ibu yang

gizinya kurang baikpun dapat menghasilkan ASI cukup tanpa makanan tambahan selama tiga bulan pertama (Endang, 2009).

Angka pencapaian ASI Eksklusif di Kota Kediri masih tergolong rendah pada tahun 2013 angka pencapaian ASI Eksklusif sebesar 69,8 \% dan mengalami penurunan pada tahun 2014 yaitu sebesar $66,0 \%$. Angka ini masih sangat jauh dari target pemenuhan pencapaian ASI Eksklusif yaitu sebesar $85 \%$

Berdasarkan uraian tersebut, maka peniliti ingin mengetahui Hubungan

penganekaragaman pangan dan pemberian ASI eksklusif dengan kejadian status gizi kurang pada balita umur 1-5 tahun.

\section{METODE}

Desain penelitian ini menggunakan metode penelitian survei analitik dengan jenis rancangan penelitian cross sectional. Pengambilan sampel menggunakan Total Sampling dengan jumlah sampel sebanyak 33 .

\section{HASIL}

Karakteristik umur responden disajikan dalam tabel1 dengan penggolongan umur responden menurut Departemen Kesehatan Republik Indonesia tahun 2009sebagai berikut :

Tabel 1 Distribusi Frekuensi Responden Berdasarkan Umur

\begin{tabular}{ccc}
\hline Umur & Frekuensi & $\begin{array}{c}\text { Persentase } \\
(\boldsymbol{\%})\end{array}$ \\
\hline $17-25$ & 4 & 14,1 \\
$26-35$ & 23 & 67,7 \\
$36-45$ & 3 & 9,1 \\
$46-55$ & 3 & 9,1 \\
Jumlah & 33 & 100 \\
\hline
\end{tabular}

(sumber : data primer 2015) 
Berdasarkan tabel 1 menunjukkan bahwa paling banyak $67,7 \%$ responden berumur 26-35 tahun. Karakteristik pekerjaan responden disajikan dalam tabel 2 dengan penggolongan pekerjaan menurut Departemen Kesehatan Republik Indonesia tahun 2009sebagai berikut:

Tabel 2 Distribusi Frekuensi Pekerjaan Responden

\begin{tabular}{ccc}
\hline Pekerjaan & Frekuensi & $\begin{array}{c}\text { Persentase } \\
(\boldsymbol{\%})\end{array}$ \\
\hline IRT & 11 & 33,6 \\
PNS & 1 & 3,0 \\
Swasta & 21 & 63,4 \\
Jumlah & 33 & 100 \\
\hline
\end{tabular}

(sumber : data primer 2015)

Berdasarkan tabel 2 menunjukkan terakhir responden disajikan dalam tabel bahwa paling banyak $63,4 \%$ responden bekerja swasta. Karakteristik pendidikan

Tabel 3 Distribusi Frekuensi Pendidikan terakhir Responden

\begin{tabular}{ccc}
\hline Pendidikan & Frekuensi & $\begin{array}{c}\text { Persentase } \\
(\boldsymbol{\%})\end{array}$ \\
\hline SMP & 7 & 21,4 \\
SMA & 25 & 75,6 \\
PT & 1 & 3,0 \\
Jumlah & 33 & 100 \\
\hline
\end{tabular}

(sumber : data primer 2015)

Berdasarkan tabel 3 menunjukkan bahwa paling banyak 75,6 \% responden berpendidikan terakhir
Karakteristik umur balita status gizi kurang disajikan dalam tabel 4 sebagai berikut

Tabel 4 Distribusi Frekuensi Umur Balita Status Gizi Kurang

\begin{tabular}{ccc}
\hline Umur (bulan) & Frekuensi & $\begin{array}{c}\text { Persentase } \\
(\boldsymbol{\%})\end{array}$ \\
\hline $12-24$ & & 27,3 \\
$25-36$ & 9 & 51,5 \\
$37-60$ & 17 & 21,2 \\
Jumlah & 7 & 100 \\
\hline
\end{tabular}

(sumber : data primer 2015)

Berdasarkan tabel 4 menunjukkan bahwa paling banyak $51,5 \%$ balita berumur 2-3 tahun. Karakteristik jenis kelamin balita status gizi kurang disajikan dalam tabel 5 sebagai berikut:

Tabel 5 Distribusi frekuensi Jenis Kelamin Balita Gizi Kurang

\begin{tabular}{ccc}
\hline Jenis kelamin & Frekuensi & $\begin{array}{c}\text { Persentase } \\
(\mathbf{\%})\end{array}$ \\
\hline Laki-laki & & 66,7 \\
Perempuan & 22 & 33,3 \\
Jumlah & 11 & 100 \\
\hline
\end{tabular}

(sumber : data primer 2015)

Berdasarkan tabel 5 menunjukkan bahwa paling banyak 66,7 \% balita berjenis kelamin laki-laki.Karakteristik berat badan balita status gizi kurang disajikan dalam tabel 6 sebagai berikut : 
Tabel 6 Distribusi Frekuensi hasil Pengukuran Berat Badan

\begin{tabular}{ccc}
\hline Berat badan $(\mathbf{k g})$ & Frekuensi & $\begin{array}{c}\text { Persentase } \\
(\boldsymbol{\%})\end{array}$ \\
\hline$<10$ & 24 & 72,7 \\
$10-15$ & 9 & 27,3 \\
Jumlah & 33 & 100 \\
\hline
\end{tabular}

(sumber : data primer 2015)

Berdasarkan tabel 6 menunjukkan penganekaragaman pangan disajikan bahwa paling banyak $72,7 \%$ berat badan dalam tabel 7 sebagai berikut :

hasil penimbangan $<10 \mathrm{~kg}$. Karakteristik

Tabel 7 Distribusi frekuensi Penganekaragaman pangan

\begin{tabular}{ccc}
\hline Penganekaragaman pangan & Frekuensi & $\begin{array}{c}\text { Persentase } \\
(\boldsymbol{\%})\end{array}$ \\
\hline Beranekaragam & 10 & 30,3 \\
Tidak Beranekaragam & 23 & 69,7 \\
Jumlah & 33 & 100 \\
\hline
\end{tabular}

(sumber : data primer 2015)

Berdasarkan tabel 7 menunjukkan bahwa paling banyak 69,7 \% penganekaragaman pangan untuk balita tidak beragam. Karakteristik pemberian ASI disajikan dalam tabel 8 sebagai berikut:

Tabel 8 Distribusi frekuensi Pemberian ASI

\begin{tabular}{ccc}
\hline Pemberian ASI & Frekuensi & $\begin{array}{c}\text { Persentase } \\
(\mathbf{\%})\end{array}$ \\
\hline Eksklusif & 13 & 39,4 \\
Tidak Eksklusif & 20 & 60,6 \\
Jumlah & 33 & 100 \\
\hline
\end{tabular}

(sumber : data primer 2015)

Berdasarkan tabel 8 menunjukkan bahwa paling banyak $60,6 \%$ balita tidak mendapat ASI eksklusif. Analisis bivariat dilakukan untuk mengetahui hubungan
Penganekaragaman pangan dengan kejadian Balita Status Gizi Kurang melalui Uji Statistik Chi-Square yang disajikan dalam tabel 9 sebagai berikut :

Tabel 9 Hasil Analisis Hubungan Penganekaragaman Pangan dengan Kejadian Gizi Kurang

\begin{tabular}{lcc}
\hline & $\begin{array}{c}\text { Nilai Odds Ratio } \\
\text { (Estimate) }\end{array}$ & $\begin{array}{c}\text { Nilai } \\
\text { Asymp. Sig (2- } \\
\text { Sided) }\end{array}$ \\
\hline Penganekaragaman Pangan & 5,518 & 0,015 \\
\hline
\end{tabular}

(sumber: hasil output uji chi-square data primer tahun 2014)

Berdasarkan tabel 9 menunjukkan bahwa nilai $\mathrm{p}<\alpha(0,05) \mathrm{p}=0,015$, maka Ho ditolak. Jadi, ada hubungan penganekaragaman pangan dengan kejadian status gizi kurang. Analisis bivariat dilakukan untuk mengetahui hubungan Pemberian ASI Eksklusif dengan kejadian Status Gizi Kurang melalui Uji Statistik Chi-Square yang disajikan dalam tabel 10 sebagai berikut : 
Tabel 10 Hasil Analisis Hubungan Pemberian ASI Eksklusif dengan Kejadian Gizi Kurang

\begin{tabular}{lcc}
\hline & $\begin{array}{c}\text { Nilai Odds Ratio } \\
\text { (Estimate) }\end{array}$ & $\begin{array}{c}\text { Nilai Asymp. } \\
\text { Sig (2-Sided) }\end{array}$ \\
\hline Pemberian ASI eksklusif & 7,034 & 0,029 \\
\hline
\end{tabular}

(sumber : hasil output uji chi-square data primer tahun 2014)

Berdasarkan tabel 10 menunjukkan bahwa nilai $\mathrm{p}<\alpha(0,05) \mathrm{p}=0,029$, maka Ho ditolak. Jadi, ada hubungan pemberian ASI eksklusif dengan kejadian status gizi kurang. Analisis multivariat dilakukan untuk mengetahui hubungan
Penganekaragaman pangan dan Pemberian ASI Eksklusif dengan kejadian Status Gizi Kurang melalui Uji Statistik Chi-Square yang disajikan dalam tabel 11 sebagai berikut :

Tabel 11 Hasil Analisis Multivariat Variabel Independen dengan Variabel Dependen

\begin{tabular}{cccc}
\hline Model & Mean Square & R & Sig. \\
\hline $\begin{array}{c}\text { Regression } \\
\text { Residual }\end{array}$ & 3.336 & .788 & $.000^{\mathrm{a}}$ \\
\hline (sumber: hasil output uji chi-square data primer tahun 2014) & & \\
\hline
\end{tabular}

Berdasarkan tabel 11 menunjukkan bahwa nilai $\mathrm{p}<\alpha(0,05) \mathrm{p}=0,000$, maka Ho ditolak. Jadi, ada hubungan

penganekaragaman pangan dan pemberian ASI eksklusif dengan kejadian status gizi kurang.

Dari hasil tabel 1 dapat diketahui bahwa umur 26-35 tahun sebesar 67,6\% menjadi responden. Umur responden yang paling banyak adalah umur 26-35 tahun dimana di umur inilah merupakan masa produktif. Umur 26-35 merupakan umur yang sudah cukup mampu untuk mendidik serta memberikan pola pengasuhan kepada anak mereka. Masa umur ini juga merupakan masa subur.

Dari hasil tabel 2 dapat diketahui bahwa tingginya persentase responden yang bekerja (swasta) menunjukkan bahwa orang tua tidak bisa secara

langsung memberikan pengawasan kepada balita, sehingga pemantauan status gizi balita tidak dapat secara langsung. 63,4\% balita diasuh oleh neneknya. Hal ini yang kemungkinan menjadi salah satu faktor dimana angka kejadian gizi kurang di Wilayah Kerja Puskesmas Kota Wilayah Utara ini menjadi semakin meningkat.

Dari hasil tabel 3 dapat diketahui bahwa sebesar 75,6\% responden berpendidikan terakhir SMA. Semakin tinggi jenjang pendidikan akan mempermudah responden untuk menerima semua masukan ataupun edukasi yang diberikan guna untuk meningkatkan derajat kesehatan serta peningkatan status gizi untuk semua anggota keluarga terutama status gizi untuk balita. Tidak jarang orang yang berpendidikan tinggi tidak mengerti atau kurang memahami pentingnya menjaga serta meningkatkan status gizi semua anggota keluarga mereka. Orang dengan pendidikan tinggi akan cenderung memikirkan pekerjaan dibanding dengan memikirkan perkembangan serta pertumbuhan daripada anggota keluarga terutama balita.

Dari hasil tabel 4 dapat diketahui bahwa umur 25-36 bulan sebesar 51,5\% mengalami gizi kurang. Anak umur 1-3 tahun merupakan konsumen pasif, artinya anak menerima makanan dari apa yang disediakan ibunya. Dengan kondisi demikian, sebaiknya anak balita diperkenalkan dengan berbagai bahan makanan.

Dari hasil tabel 5 dapat diketahui bahwa Balita yang menderita gizi kurang sebesar $66,7 \%$ di wilayah kerja Puskesmas kota wlayah utara paling banyak laki-laki. Aktivitas anak laki-laki cenderung lebih aktif dibanding dengan anak perempuan. Jumlah asupan kalori yang diterima tidak sebanding dengan jumlah kalori yang dikeluarkan. Anak 
susah makan tetapi anak terus melakukan aktivitas yang sangat banyak.

Berdasarkan tabel 6 sebesar $72,7 \%$ menunjukkan rata- rata berat badan yang dihasilkan dari hasil pengukuran yaitu < $10 \mathrm{~kg}$. Hasil penelitian menghasilkan bahwa, kurangnya berat badan terjadi karena balita susah untuk diberi makanan.

Berdasarkan tabel 7 dapat diketahui bahwa persentase penganekaragaman sebesar $69,7 \%$ adalah tidak beranekaragam. Sebagian besar responden tidak memberikan makanan yang seimbang setiap harinya dalam memberikan makanan kepada balita. Ibu hanya memberikan makanan kepada anaknya dengan menu saji makanan setiap hari adalah nasi, lauk, serta sayur. Untuk konsumsi sayur sendiri sangat jarang intensitas pemberiannya, sedangkan untuk buah hampir sebagian balita jarang diberikan buah setiap hari. Namun untuk konsumsi susu balita mendapatkannya setiap hari. Hasil penelitian menunjukkan bahwa tingkat konsumsi sayur serta buah untuk kalangan balita yang masih sangat rendah sehingga proses tumbuh kembang balita akan terganggu.

Berdasarkan tabel 8 dapat dikatahui bahwa persentase pemberian ASI sebesar $60,6 \%$ tidak eksklusif. Sebagian besar responden tidak memberikan ASI secara Eksklusif karena sebagian ibu lebih memilih untuk memberikan susu formula serta memberikan makanan tambahan pada balita berumur $<6$ bulan.

Berdasarkan tabel 9 dapat diketahui bahwa penganekaragaman memiliki hubungan terhadap kejadian status gizi kurang pada balita. Hal ini ditunjukkan dengan nilai signifikansi sebesar 0,015 , nilai odds ratio 5,518 hal ini menunjukkan bahwa balita berumur 1-5 tahun yang tidak mendapatkan penganekaragaman panganberisiko 6 kali lipat untuk menderita gizi kurang.

\section{PEMBAHASAN}

Hasil penelitian ini sejalan dengan pernyataan dari BAPPENAS (2011) yang menyatakan bahwa konsumsi makanan yang beranekaragam, bergizi seimbang dan aman di tingkat rumah tangga akan berdampak pada semakin beratnya masalah gizi kurang pada balita.

Berdasarkan tabel 10 dapat dikatahui bahwa pemberian ASI Eksklusif memiliki hubungan dengan kejadian gizi kurang pada balita. Hal ini ditunjukkan dengan nilai signifikansi dari hasil pengolahan data didapatkan nilai sebesar 0,029 , nilai odds ratio yaitu 7,034 artinya, anak yang berumur 1-5 tahun dengan pemberian ASI yang tidak eksklusif lebih berisiko akan mengalami gizi kurang 7 kali lipat.

Hasil penelitian ini sejalan dengan penelitian yang dilakukan oleh Endang (2009) yang menyatakan bahwa bayi 612 bulan yang mendapat ASI Eksklusif berisiko 0,44 kali menderita gizi kurang dibanding dengan yang tidak mendapat ASI eksklusif 2,3 kali beriko terkena gizi kurang. Hasil penelitian diatas secara umum menunjukkan bahwa pemberian ASI eksklusif pada bayi selama 6 bulan pertama kehidupannya dapat mencegah gizi kurang. Secara teori hal itu beralasan dimana air susu ibu sangat penting untuk memenuhi kebutuhan bayi dalam segala hal.

Berdasarkan tabel 11 dapat dikatahui bahwa terdapat hubungan antara penganekaragaman pangan dan pemberian ASI eksklusif dengan kejadian status gizi kurang. Nilai sig sebesar $0,000<$ dari $\alpha(0,05)$. Analisa multivariat menunjukkan bahwa secara bersamasama antara variabel penganekaragaman pangan dan pemberian ASI memiliki pengaruh terhadap gizi kurang. Kekuatan hubungan atau korelasi sebesar 78,8 hal ini menunjukkan bahwa hubungan yang terjadi sangat kuat.

\section{KESIMPULAN}

Penganekaragaman pangan dan pemberian ASI Eksklusif secara bersama-sama memiliki hubungan yang 
kuat dengan kejadian gizi kurang pada balita umur 1-5 tahun.

\section{SARAN}

Sosialisasi kepada ibu-ibu posyandu tentang faktor risiko yang dapat

menyebabkan gizi kurang serta pentingnya upaya penganekaragaman pangan untuk balita melalui penyuluhan yang dilakukan oleh pihak Puskesmas guna penurunan angka kejadian gizi kurang.

Meningkatkan peran kader posyandu melalui pelatihan dan pengarahan yang disiapkan oleh pihak Puskesmas

mengenaiupaya penanganan serta pencegahan gizi kurang pada balita.

\section{DAFTAR RUJUKAN}

Andriani, Merryana. 2012. Peranan Gizi Dalam Siklus Kehidupan. Jakarta: Kencana Prenada Media Group.

BAPPENAS. 2011. Rencana Aksi Nasional Pangan dan Gizi

Dinkes Jatim. 2010. Profil Kesehatan Provinsi Jawa Timur Tahun 2010.

Dinkes Kota Kediri. 2013. Data Dinas Kesehatan Kota Kediri Tahun 2014. 2014. Data Dinas Kesehatan Kota Kediri Tahun 2014.

Fatimah, Sari. 2008. Faktor - faktor yang Berkontribusi Terhadap Status Gizi pada Baita di Kecamatan Ciawi Kabupaten Tasikmalaya. Jurnal Vol 10 No. XVIII Maret 2008 -
September 2008 (diakses tanggal 23 Oktober 2014)

Kemenkes RI. 2013. Profil Kesehatan Indonesia Tahun 2013.

Krino, Agus Budianto. 2009. Dasardasar Ilmu Gizi. Malang: UMM Press.

Meiliany. 2011. Faktor Risiko Status Gizi Kurang pada Bayi Umur Enam Bulan. Jurnal. Poltekkes RI Jakarta.

Putri, Sari. 2012. Hubungan Tingkat Pengetahuan Suami Tentang Pemberian ASI Terhadap Motivasi Ibu Dalam Menyusui Di Kelurahan Kemiri Muka

Kota Depok. Skripsi. Universitas Indonesia (Diakses tanggal 2 Januari 2015).

RISKESDAS.2013. Riset Kesehatan Dasar 2013.

Supariasa. 2012. Penilaian Status Gizi. Jakarta. EGC

WHO.2012. Joint UNICEF - WHO The World Bank Child Malnutrition Database: Estimates for 2012 and Launch of Intractive Data Dashboards.

Widyastuti, Endang. 2009. Hubungan Riwayat Pemberian ASI Eksklusif dengan Status Gizi Bayi 6-12 Bulan di Provinsi Nusa Tenggara Barat (NTB) Tahun 2007. Tesis. Universitas Indonesia (diakses tanggal 6 Oktober 2014) 